\title{
Inducibility of Atrial Fibrillation Before and After Radiofrequency Catheter Ablation of Accessory Atrioventricular Connections
}

\author{
STEVEN J. KALBFLEISCH, M.D., RAFEL EL-ATASSI, M.D., \\ HUGH CALKINS, M.D., JONATHAN J. LANGBERG, M.D., \\ and FRED MORADY, M.D. \\ From the Division of Cardiology, [Department of Internal Medicine, University of Michigan Medical Center, \\ Ann Arbor, Michigan
}

\begin{abstract}
Inducibility of Atrial Fibrillation. Introduction: The purpose of this study was to evaluate the inducibility of atrial fibrillation in patients with an accessory atrioventricular connection (AAVC) and to determine if the inducibility of atrial fibrillation is altered after successful radiofrequency catheter ablation of the AAVC.

Methods and Results: Thirty-seven patients with an AAVC and 36 control patients were prospectively evaluated using a standardized atrial pacing protocol. The high right atrium was paced using a 25-beat drive train, 1.5-second intertrain pause, $10-\mathrm{mA}$ pulse amplitude, and 2msec pulse duration at cycle lengths of 250 to $100 \mathrm{msec}$, in 10 -msec decrements. Pacing was performed twice at each cycle length. Thirty patients with an AAVC underwent repeat atrial overdrive pacing after successful radiofrequency ablation of the AAVC. Atrial fibrillation was induced in $26(70 \%)$ patients with an AAVC and $22(61 \%)$ controls $(P=N S)$. Atrial flutter was induced in $11(30 \%)$ patients with an AAVC and $13(36 \%)$ controls $(P=N S)$. The cumulative percentage of patients with atrial fibrillation/flutter induced at each pacing cycle length was the same in each group. There was no difference in the duration of atrial fibrillation/flutter between control patients and patients with an AAVC. Among the 30 patients who underwent repeat atrial overdrive pacing after radiofrequency ablation of an AAVC, there was no difference in the inducibility or duration of atrial fibrillation/atrial flutter after ablation compared to baseline.

Conclusion: These findings indicate that the vulnerability of the atrium to fibrillate in response to atrial pacing is independent of the presence of an AAVC. ( $J$ Cardiovasc Electrophysiol, Vol. 4, pp. 499-503, October 1993)
\end{abstract}

atrial fibrillation, Wolff-Parkinson-White syndrome, radiofrequency catheter ablation

\section{Introduction}

Long-term follow-up studies after successful surgical or catheter ablation of accessory atrioventricular connections (AAVC) have shown that the incidence of spontaneously occurring atrial fibrillation is significantly reduced. ${ }^{1-3}$ The expla-

Address for correspondence: Fred Morady, M.D., Division of Cardiology, Department of Internal Medicine, University of Michigan Medical Center, 1500 East Medical Center Drive, Ann Arbor, MI 48109. Fax: 313-936-7641.

Manuscript received 22 January 1993; Accepted for publication 24 March 1993. nation for this reduction in the incidence of atrial fibrillation after ablation of AAVCs has been unclear. While some studies have suggested that this may be due to elimination of atrioventricular reciprocating tachycardia that can degenerate into atrial fibrillation, ${ }^{1,3}$ another study suggested that the vulnerability of the atrium to atrial fibrillation may be reduced. ${ }^{2}$ The purpose of this prospective study was to evaluate the inducibility of atrial fibrillation in patients with AAVCs and to determine if the inducibility of atrial fibrillation is altered after successful radiofrequency catheter ablation of the AAVC. 


\section{Methods}

Thirty-seven patients with AAVCs and 36 control patients who did not have an AAVC were prospectively evaluated using a standardized atrial pacing protocol. The characteristics of the patients are described in Table 1. Among the patients with an AAVC, the AAVC was overt in 30 and concealed in 7; the location was left sided in 25 and right sided or posteroseptal in 12 . The control group was composed of 19 patients with ventricular arrhythmias, 9 patients with syncope of unknown origin, and 8 patients with palpitations of unknown etiology. Thirty-six patients with an AAVC did not have structural heart disease and one had congenital pulmonic stenosis. Twenty patients in the control group did not have heart disease, 11 had coronary artery disease, 3 had an idiopathic dilated cardiomyopathy, and 2 had valvular heart disease.

\section{Electrophysiologic Study/Pacing Protocol}

All patients provided informed consent and underwent an electrophysiologic test after discontinuation of all antiarrhythmic medications for at least 48 hours. The sinus cycle length, $\mathrm{AH}$ interval, HV interval, atrial effective refractory period, $\mathrm{P}$ wave duration, PA interval at the His position, atrioventricular block cycle length, and ventriculoatrial block cycle length were determined in each patient. The presence of an AAVC was determined using standard electrophysiologic techniques. ${ }^{4}$

Atrial overdrive pacing was performed in each patient using a standardized protocol. The high right atrium was paced using a 25-beat drive train, 1.5-second intertrain pause, $10-\mathrm{mA}$ pulse amplitude, and 2-msec pulse duration. Pacing was performed at cycle lengths of 250 to $100 \mathrm{msec}$ in 10msec decrements. Pacing was performed twice at each pacing cycle length. Pacing was discontinued after the induction of either sustained ( $\geq 30$

TABLE 1

Patient Characteristics

\begin{tabular}{lccc}
\hline & $\begin{array}{c}\text { Patients with } \\
\text { an AAVC }\end{array}$ & $\begin{array}{c}\text { Control } \\
\text { Patients }\end{array}$ & $\begin{array}{c}\text { P } \\
\text { Value }\end{array}$ \\
\hline $\begin{array}{l}\text { Number of patients } \\
\text { Age (years, }\end{array}$ & 37 & 36 & \\
$\quad$ mean \pm SD) & $35 \pm 14$ & $53 \pm 15$ & $<0.001$ \\
Males/Females & $26 / 11$ & $23 / 13$ & $\mathrm{NS}$ \\
Heart disease present & 1 & 16 & $<0.001$ \\
$\begin{array}{l}\text { History of atrial } \\
\text { fibrillation }\end{array}$ & 7 & 3 & $\mathrm{NS}$ \\
\hline AAVC = accessory atrioventricular connection.
\end{tabular}

AAVC $=$ accessory atrioventricular connection. sec) atrial fibrillation or flutter or after three episodes of nonsustained $(<30 \mathrm{sec})$ atrial fibrillation or flutter. The single longest episode was recorded in each patient and patients were classified as having either atrial fibrillation or atrial flutter. Atrial fibrillation and flutter were defined using the criteria of Wells et al..$^{5,6}$ Atrial flutter was defined as a regular atrial tachycardia with an atrial cycle length of 170 to $240 \mathrm{msec}$, uniform intracardiac atrial electrogram morphology, and an isoelectric interval between atrial complexes. Irregular atrial tachycardias with variable intracardiac electrogram morphology and without isoelectric segments were considered to be atrial fibrillation. A subgroup of 30 patients with an AAVC underwent repeat atrial overdrive pacing after successful radiofrequency ablation of the AAVC. None of these 30 patients had received antiarrhythmic therapy during the course of their procedure. The techniques utilized for radiofrequency ablation of AAVCs have been previously described?

\section{Results}

Atrial fibrillation was induced in $26(70 \%)$ patients who had an AAVC, compared to $22(61 \%)$ control patients $(\mathrm{P}=\mathrm{NS})$. Atrial flutter was induced in $11(30 \%)$ patients with an AAVC compared to $13(36 \%)$ controls $(\mathrm{P}=\mathrm{NS})$. The induced arrhythmia was sustained in $23(65 \%)$ patients with an AAVC, and $24(67 \%)$ control patients and nonsustained in $14(38 \%)$ patients with an AAVC and $11(31 \%)$ control patients $(\mathrm{P}=\mathrm{NS}$ between the groups). In patients with a sustained arrhythmia, the induced arrhythmia was atrial fibrillation in 16 (70\%) and atrial flutter in $7(30 \%)$ patients with an AAVC, and atrial fibrillation in $13(54 \%)$ and atrial flutter in $11(46 \%)$ control patients $(\mathrm{P}=\mathrm{NS}$ between the groups). The mean duration of nonsustained atrial flutter was $19 \pm 5$ seconds and of nonsustained atrial fibrillation was $16 \pm 7$ seconds. There was no difference between patients with an AAVC and control patients with respect to the baseline sinus cycle length, AH interval, atrial effective refractory period, $\mathrm{P}$ wave duration, or $\mathrm{PA}$ interval at the His position (Table 2). As expected, the patients with an AAVC had shorter baseline HV intervals, and atrioventricular and ventriculoatrial block cycle lengths (Table 2). There were no differences in the mean pacing cycle lengths that induced atrial fibrillation or flutter in the patients with an AAVC (198 $\pm 30 \mathrm{msec})$ compared to controls ( $193 \pm 25 \mathrm{msec})$, and there was no difference in the mean pacing cycle length needed to 
TABLE 2

Baseline Electrophysiologic Data

\begin{tabular}{lccc}
\hline & $\begin{array}{c}\text { Patients with } \\
\text { an AAVC }\end{array}$ & $\begin{array}{c}\text { Control } \\
\text { Patients }\end{array}$ & $\begin{array}{c}\text { P } \\
\text { Value }\end{array}$ \\
\hline $\begin{array}{l}\text { Sinus cycle length } \\
\text { (msec) }\end{array}$ & $799 \pm 165$ & $792 \pm 175$ & NS \\
$\begin{array}{l}\text { AH interval (msec) } \\
\text { HV interval (msec) }\end{array}$ & $88 \pm 18$ & $96 \pm 32$ & NS \\
$\begin{array}{l}\text { Atrial ERP (msec) } \\
\text { P wave duration }\end{array}$ & $223 \pm 28$ & $45 \pm 10$ & 0.0001 \\
$\quad(m s e c)$ & & $227 \pm 28$ & NS \\
PA interval at His & $90 \pm 11$ & $89 \pm 13$ & NS \\
$\quad(m s e c)$ & $22 \pm 10$ & $26 \pm 10$ & NS \\
AVBCL (msec) & $296 \pm 51$ & $365 \pm 72$ & 0.0001 \\
VABCL (msec) & $282 \pm 57$ & $433 \pm 105$ & 0.0001 \\
\hline ERP & & & \\
\hline
\end{tabular}

ERP = effective refractory period; $\mathrm{AVBCL}=$ atrioventricular block cycle length; VABCL = ventriculoatrial block cycle length; AAVC = accessory atrioventricular connection.

induce atrial fibrillation $(194 \pm 28 \mathrm{msec})$ compared to atrial flutter $(198 \pm 25 \mathrm{msec})$ when both patient groups were considered together. Both control patients and patients with an AAVC had the same response to atrial pacing at each stage of the pacing protocol (Fig. 1). At each step of the pacing protocol, the cumulative yield of atrial fibrillation/flutter was similar in both groups of patients.

\section{Effects of Radiofrequency Ablation}

Among the 30 patients who underwent radiofrequency ablation of an AAVC, there was no dif- ference in the inducibility or duration of atrial fibrillation or flutter after radiofrequency ablation of the AAVC compared to baseline (Table 3). The mean pacing cycle length required to induce atrial fibrillation/flutter after ablation $(195 \pm 25 \mathrm{msec})$ was not different than before ablation $(199 \pm 30 \mathrm{msec})$. Before and after radiofrequency ablation there was no difference in the response to the atrial pacing protocol (Fig. 2). At each step of the pacing protocol, the cumulative yield of atrial fibrillation/flutter was similar before and after radiofrequency ablation of the AAVC.

\section{Discussion}

This study demonstrates that a standardized, aggressive atrial pacing protocol results in the induction of atrial fibrillation or flutter in nearly $100 \%$ of patients and that the incidence of atrial fibrillation or flutter induction in patients with AAVCs is no different than in other patients referred for electrophysiologic evaluation. The other major finding of this study is that the incidence of atrial fibrillation induction, its duration, and the pacing cycle length required for induction are not altered after radiofrequency ablation of the AAVC. These findings indicate that the vulnerability of the atria to fibrillate in response to atrial burst pacing is independent of the presence of an AAVC.

Previous studies evaluating atrial fibrillation

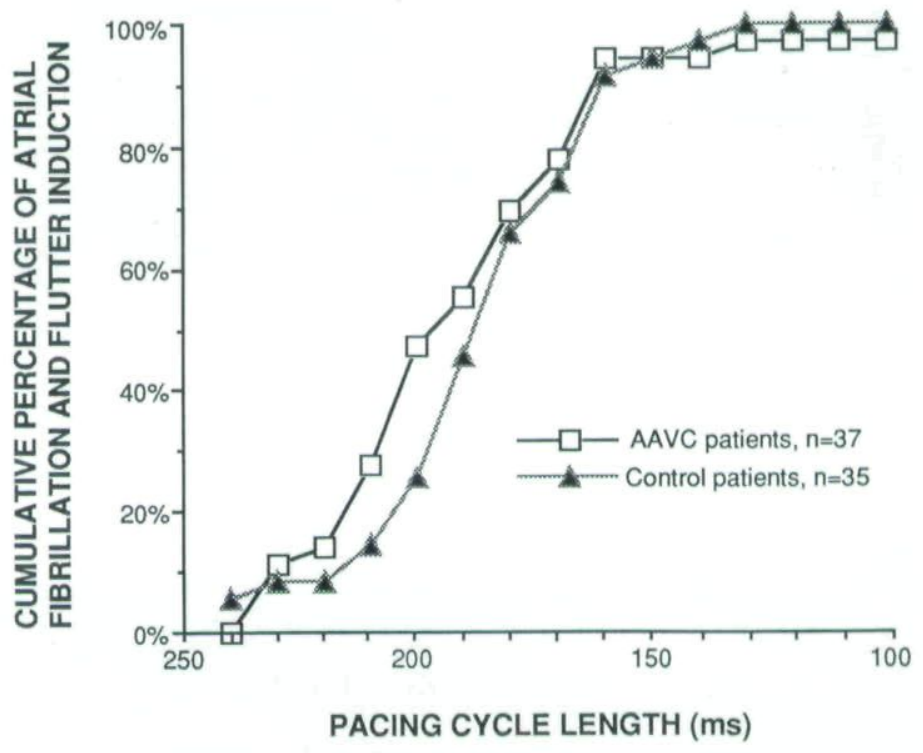

Figure 1. The cumulative yield of atrial fibrillation and flutter at each pacing cycle length of the atrial overdrive pacing protocol for patients with accessory atrioventricular connections (AAVC) and control patients. There was no difference between the two groups with respect to the cumulative yield of atrial fibrillation and flutter at each step in the pacing protocol. 
TABLE 3

Results of Atrial Pacing Before and After Ablation in 30 Patients with an Accessory Atrioventricular Connection

\begin{tabular}{lcc}
\hline & $\begin{array}{c}\text { Before } \\
\text { Ablation }\end{array}$ & $\begin{array}{c}\text { After } \\
\text { Ablation }\end{array}$ \\
\hline Arrhythmia Induced & & \\
$\quad$ Atrial fibrillation & 21 & 20 \\
$\quad$ Atrial flutter & 9 & 10 \\
Duration of Arrhythmia & & \\
$\quad$ Sustained & 21 & 22 \\
$\quad$ Nonsustained & 9 & 8 \\
\hline
\end{tabular}

$\mathrm{P}=\mathrm{NS}$. There was no difference before and after ablation in the arrhythmias induced or the duration of the arrhythmias.

inducibility before and after surgical or catheter ablation of AAVCs have found a lower incidence of inducibility after successful ablation. ${ }^{1,2}$ Sharma et al. ${ }^{1}$ studied 38 patients before and after surgical ablation of an AAVC. During the presurgical electrophysiologic study, atrial pacing at cycle lengths as short as 120 to $150 \mathrm{msec}$ were used and atrial fibrillation was induced in 32 of the 38 patients; during the follow-up electrophysiologic study, no patient had inducible atrial fibrillation, but atrial pacing was limited to cycle lengths greater than or equal to the atrioventricular block cycle lengths. Haissaguerre et $\mathrm{al}^{2}{ }^{2}$ found a lower incidence of atrial fibrillation induction in patients with a history of atrial fibrillation after successful direct current ablation of AAVCs. In their study, only single or double atrial extrastimuli were used to induce atrial fibrillation and rapid atrial overdrive pacing was not performed.

The major difference between our study and these previous studies is the atrial pacing protocols that were utilized. Our study used an aggressive atrial pacing protocol that was operator independent and standardized to be performed the same way in each case. The study of Sharma et al. ${ }^{1}$ used different pacing protocols during the preand postablation electrophysiologic tests. In the study by Haissaguerre et al., ${ }^{2}$ the pacing protocol used to induce atrial fibrillation was less aggressive than in our study and it is not clear that the same extrastimulus pacing techniques were used pre- and postablation, since the authors did not compare the coupling intervals or the number of extrastimuli used.

Although the pacing protocol utilized in this study was aggressive and induced atrial flutter or fibrillation in nearly $100 \%$ of patients, this does not limit its ability to evaluate the vulnerability of the atria to fibrillate. As Figures 1 and 2 show, less aggressive protocols that would have limited the pacing cycle lengths to $>150 \mathrm{msec}$ would have simply reduced the total percentage of patients with atrial fibrillation or flutter induced but would not have produced any difference in inducibility

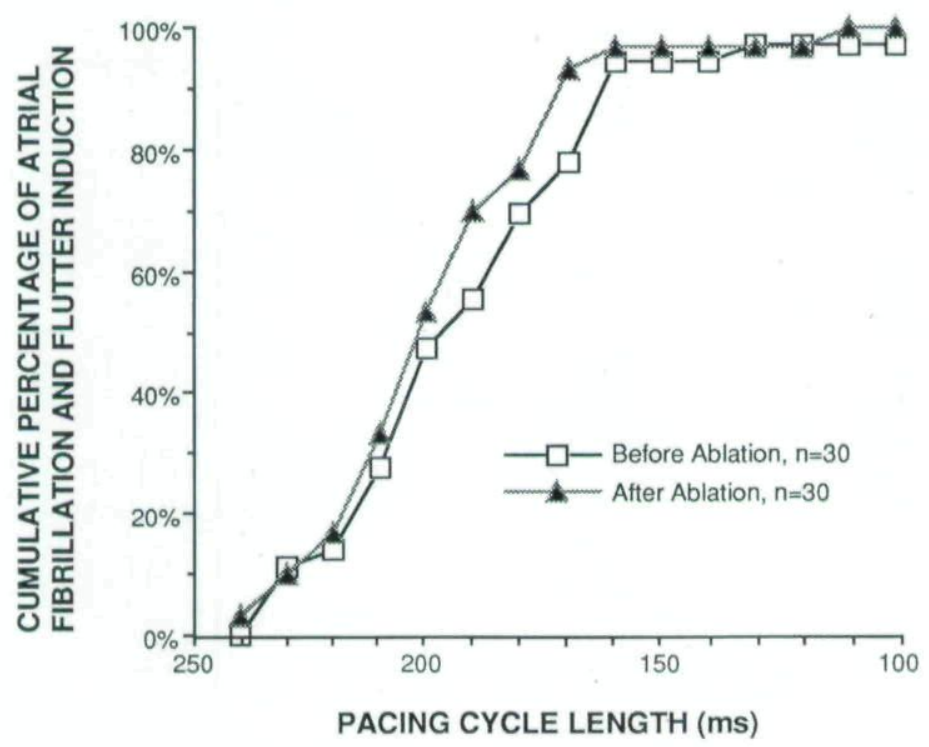

Figure 2. The cumulative yield of atrial fibrillation and flutter at each pacing cycle length of the atrial overdrive pacing protocol in patients before and after successful radiofrequency catheter ablation of accessory atrioventricular connections. There was no difference in the cumulative yield of atrial fibrillation or flutter at each step in the pacing protocol before and after successful ablation. 
between the different patient groups. There was a small but insignificant difference in the incidence of atrial fibrillation and atrial flutter induction between patients with an AAVC and control patients at pacing cycle lengths $>180 \mathrm{msec}$. However, as Figure 1 shows, this apparent difference was due to only a $10-\mathrm{msec}$ shift to the right in the curve for the control patients.

A limitation of this study is that only one method for assessing the vulnerability of the atrium to fibrillate was used. It is possible that other methods that utilized atrial extrastimulus techniques, different durations of burst pacing, or different pacing-pulse amplitudes may have had different results.

The results of this study suggest that it is not a change in the vulnerability of the atrium to fibrillate that accounts for the reduction in the incidence of spontaneous atrial fibrillation after ablation of AAVCs, but instead it is some other factor such as elimination of atrioventricular reciprocating tachycardia or attenuation of ventriculoatrial conduction.

Acknowledgment: The authors are grateful to Heidi Williams for her secretarial assistance in the preparation of this manuscript.

\section{References}

1. Sharma A, Klein G, Guiraudon G, et al: Atrial fibrillation in patients with Wolff-Parkinson-White syndrome: Incidence after surgical ablation of the accessory pathway. Circulation 1985;1:161-169.

2. Haissaguerre M, Fischer B, Labbe T, et al: Frequency of recurrent atrial fibrillation after catheter ablation of overt accessory pathways. Am J Cardiol 1991;69:493-497.

3. Roark S, McCarthy E, Lee K, et al: Observations on the occurrence of atrial fibrillation in paroxysmal supraventricular tachycardia. Am J Cardiol 1986;57: 571-575.

4. Josepheson ME: Clinical Cardiac Electrophysiology: Techniques and Interpretations. Lea \& Febiger, Philadelphia, 1993.

5. Wells JL, Karp RB, Kouchoukos NT, et al: Characterization of atrial fibrillation in man: Studies following open heart surgery. PACE 1978;1:426-438.

6. Wells JL, MacLean WAH, James TN, et al: Characterization of atrial flutter: Studies in man after open heart surgery using fixed atrial electrodes. Circulation 1979;60:3:665-673.

7. Calkins H, Langberg J, Sousa J, et al: Radiofrequency catheter ablation of accessory atrioventricular connections in 250 patients: Abbreviated therapeutic approach to Wolff-Parkinson-White syndrome. Circulation 1992;85:1337-1346. 
This document is a scanned copy of a printed document. No warranty is given about the accuracy of the copy. Users should refer to the original published version of the material. 